\title{
Entre la ciencia ficción y las ciencias sociales: el "lado oscuro" de las ciudades americanas
}

\begin{abstract}
From the Metropolis de Fritz Lang to the city-planet of Coruscant, invented by George Lucas in the films of Star Wars, the city of the future (or of another galaxy) seems designed only to reflect the "dark side" of contemporary megalopolis, which suffer problems and dysfunctionality which are presented as insurmountable: traffic jams, contamination, environmental degradation, ethnic conflicts, deficienct public services, rising social and spatial disparities, daily violence. In order to develop this imaginary geography of fear, Latin American cities are often a source of inspiration for science fiction authors because they seem to them simultaneously both strange and foreign, old and modern, welcoming and dangerous. It is this tight relationship between representations of the Latin American city and the reality of the imaginary cities that we explore here, in a study of geofiction based on the comparison of two parallel urban worlds that play an important role in our collective mentalities.
\end{abstract}

Keywords: science fiction, social sciences, imaginary cities, american cities, geography of fear

\section{Resumen}

Desde la Metrópolis de Fritz Lang hasta el planeta-ciudad de Coruscant inventado por George Lucas en las películas de Star Wars, la ciudad del futuro (o la de otra galaxia) parece diseñada solo para reflejar el lado oscuro de las megalópolis contemporáneas, que padecen problemas y disfunciones presentados como insuperables: congestión, contaminación, degradación del medio ambiente, deficiencia de los servicios públicos, crecimiento de las disparidades sociales y espaciales, conflictos étnicos, violencia cotidiana. Para desarrollar esta geografía imaginaria del miedo, las ciudades latinoamericanas son a menudo una fuente de inspiración para los autores de la ciencia ficción, ya que les resultan a la vez extrañas y extranjeras, antiguas y modernas, acogedoras y peligrosas. Es esta estrecha relación entre las representaciones de la ciudad latinoamericana y la realidad de las ciudades imaginarias que proponemos explorar aquí, en un estudio de geoficción, basado en la comparación de dos mundos urbanos paralelos que juegan un papel importante en nuestras mentalidades colectivas.

Palabras claves: ciencia ficción, ciencias sociales, ciudades imaginarias, ciudades americanas, geografía del miedo 


\section{Introducción: imaginarios urbanos y ciudades imaginarias}

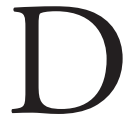
esde la Metropolis de Fritz Lang hasta el planeta-ciudad de Coruscant ${ }^{1}$ inventado por George Lucas en las películas de Star Wars (la Guerra de las Galaxias), la ciudad del futuro (o la de otra galaxia) parece diseñada solo para reflejar el lado oscuro de las megalópolis contemporáneas, que padecen problemas y disfunciones presentados como insuperables: congestión, contaminación, degradación del medio ambiente, deficiencia de los servicios públicos, crecimiento de las disparidades sociales y espaciales, conflictos étnicos, violencia permanente...

En los años ochenta, tanto los periodistas como los académicos convirtieron a la Ciudad de México en el símbolo de estas ciudades gigantes, que se concebían como a punto de estallar o desvanecerse. En 1986, un año después del terremoto que azotó el centro histórico de la capital mexicana, la revista francesa Autrement colocaba a México "entre la esperanza y la condena", título voluntariamente provocativo. En 1987, Miguel Messmacher publicaba en México un estudio que hacía hincapié en las disfunciones de una megalópolis que las autoridades no lograban controlar (Messmacher, 1987). El año siguiente, Claude Bataillon y Louis Panabière consideraban que la ciudad más grande del mundo ya no podía garantizar el alojamiento, asegurar el trabajo y organizar los desplazamientos de sus 20 millones de habitantes (Bataillon \& Panabière, 1988). Siguiendo el mismo camino, los investigadores estadounidenses contribuyeron ampliamente a denunciar el desastre inminente que amenazaba a sus infelices vecinos del sur, alimentando por sus escritos la imaginación de los autores de ciencia ficción (Kandell, 1988).

Para calificar (o descalificar) a México, se crearon incluso neologismos despreciativos que

École des Hautes Études en Sciences Sociales (EHESS) - Groupe de Géographie Sociale et d'Études Urbaines (GGSEU), París, Francia. E-mail: alain.musset@ehess.fr.

En la saga de películas de La Guerra de las Galaxias, Coruscant es uno de los planetas más poblados de la galaxia, es un planeta del tipo ecumenópolis, o sea, es una ciudad que cubre el planeta entero. podrían perfectamente aplicarse a la capital de la galaxia de Star Wars. Así pues, según François Tomas, la megaciudad latinoamericana no era sino el prototipo de la monstruópolis, una ciudad abrumada por todos los males de la sociedad moderna: "la superpoblación, los tugurios y los barrios de chabolas o asentamientos irregulares, el subempleo, el trabajo informal y la pobreza, la infancia abandonada, la delincuencia y el crimen organizado, la contaminación y las catástrofes ecológicas, etc." (Tomas, 1999: p. 283-289). En su Historia de México, Serge Gruzinski colocaba por su parte la vida de los ciudadanos actuales de la antigua Tenochtitlán bajo la señal del apocalipsis día a día (Gruzinski, 1996).

No es pues una casualidad si la acción de la famosa película de ciencia ficción Total Recall ${ }^{2}$ comienza en una ciudad del futuro que no es completamente de ciencia ficción: cuando Arnold Schwarzenegger sale del Metro, perseguido por sus enemigos, el espectador bien informado descubre que el escenario elegido por Paul Verhoeven no es sino la estación de metro Insurgentes, ubicada en el centro de la metrópolis mexicana. Según el realizador, se trataba de poner en escena un mundo especialmente opresor, situado fuera de la escala humana. La red subterránea de México, cuyo estilo se basa en el movimiento neobrutalista nacido en Inglaterra a mediados de los años 1950 bajo los auspicios de Margaret Alison y Peter Smithson, correspondía perfectamente a sus intenciones puesto que "su lado oscuro, muy pesado y principalmente a base de hormigón, dio a la película un tipo de decorado con una arquitectura muy peculiar" (Verhoeven, 2003) ${ }^{3}$. Bastó para el equipo de rodaje con pintar en gris metalizado el conjunto de los pasillos, de las paredes y vagones para dar al espectador la ilusión de descubrir una metrópolis imaginaria cuando se trataba de una ciudad real: de México a Coruscant pasando por el planeta Marzo, el camino no es tan largo como parece...

\footnotetext{
2 Desafio total en España y El vengador del futuro en Latinoamérica.

El neobrutalismo (new brutalism) citado por Verhoeven se basa en la obra de Le Corbusier, más particularmente con su unidad de habitación de Marsella (Francia). Conoció su apogeo en los años 1960-1970, con arquitectos tan famosos como Paul Rudolf (EE-UU) o Kenzo Tange (Japón).
} 
Para desarrollar esta geografía imaginaria del miedo y el encerramiento, las ciudades latinoamericanas son a menudo una fuente de inspiración para los autores de ciencia ficción porque les resultan a la vez extrañas y extranjeras, antiguas y modernas, acogedoras y peligrosas. En su última novela, Mantra, Rodrigo Fresán recuerda a este respecto que, en los años 1953-1954, unos inspectores del FBI habían propuesto a Philip K. Dick y a su mujer pagarles un año de estudios en la UNAM, a cambio de informaciones sobre los grupos estudiantiles más politizados. Fresán destaca que el futuro autor de Blade Runner (o más bien de Do androids dream of electric sheep?) rechazó esta oferta generosa, pero se imagina que, hundido en el universo alucinante de la nueva Tenochtitlán, habría podido escribir tres o cuatro novelas de ciencia ficción al mes (Fresán, 2006: p. 198).

Es esta estrecha relación entre las representaciones (Bailly, 1995: p. 372) de la ciudad latinoamericana y la realidad de las ciudades imaginarias que proponemos explorar aquí, en un estudio de geoficción basado en el desciframiento de los juegos de espejos que acercan, consciente o inconscientemente, dos mundos urbanos paralelos e influyen sobre nuestra manera de percibirlos. Se trata pues de poner en tela de juicio la influencia recíproca que ejercen sobre nuestra visión de la ciudad no sólo los relatos de ciencia ficción, sino también los estudios de sociología urbana o geografía social y las experiencias diarias de un espacio cada vez menos vivido y más mediatizado. En la primera parte de este trabajo veremos cómo las ciudades de ciencia ficción basan parte de su existencia virtual tanto en las ciudades latinoamericanas contemporáneas, como en los imaginarios prehispánicos (Pirámides aztecas y ciudades del futuro). Luego, planteamos la transposición de nuestra división internacional del trabajo hacia universos que parecen muy distantes, pero no son más que una imagen apenas deformada de situaciones reales (Maquiladoras galácticas). En la última parte, La ciudad y sus peligros, se muestra que la ciencia ficción denuncia las disfunciones reales o imaginarias que amenazan la existencia de nuestras metrópolis en tanto objetos políticos, que son reducidos a territorios dominados por el miedo.

\section{Pirámides aztecas y ciudades del futuro}

En el universo de la ciencia ficción, el planetaciudad de Coruscant es sin duda alguna el mundo urbano imaginario que ha sido presentado de manera mas detenida y precisa porque sirvió de escenario no sólo para las tres últimas películas rodadas por George Lucas (La amenaza fantasma, El ataque de los clones y La venganza de los Sith) sino también para muchas novelas, historietas o caricaturas y juegos electrónicos cuyos héroes están todos relacionados directa o indirectamente con la historia original (Musset, 2005). Ahora bien, la capital de la República, y luego del Imperio galáctico, juega a la vez el papel de modelo y contra-modelo cuyos paisajes y estructuras sociales se inspiran tanto en las ciudades gigantes de la costa Atlántica de los Estados Unidos como en las grandes metrópolis que estructuran y organizan el espacio latinoamericano: México, Lima, São Paulo... Sin olvidar las ciudades fronterizas del Norte de México o las favelas de Río de Janeiro y Caracas.

De hecho, la capital galáctica aparece como una amenaza imaginaria de nuestras sociedades modernas: la urbanización total de las formas del hábitat producida por la expansión urbana incontrolada (urban sprawl). Como consecuencia de este proceso urbanístico, se extiende un verdadero bosque de rascacielos que forma una extraordinaria skyline, cuyos límites no se pueden imaginar porque ya desaparecieron: "Estaban en la cumbre de un café, $3 \mathrm{Km}$. sobre la superficie de Coruscant, el planeta reducido a una ciudad sin fin. Abajo de la barandilla de la terraza, se veían los rascacielos extendidos hasta al horizonte, un cielo anaranjado donde la lluvia amenazaba y la puesta del sol detrás de las nubes de tormenta" (Allston, 2003).

Si fuera necesario encontrar un equivalente o un modelo para este mundo caracterizado por su arquitectura vertical, sería necesario buscarlo en São Paulo, capital económica de Brasil. Desde la cumbre del Edificio Italia se contempla un extenso océano de edificios, que cuentan a veces varias decenas de pisos y encubren las partes bajas de la ciudad, haciendo desaparecer el trazado regular de las calles y avenidas. Se transforma así el paisaje urbano en un laberinto semejante al caos urba- 
nístico de Coruscant. Considerada como una de las mayores aglomeraciones del mundo, la región metropolitana de São Paulo sólo cuenta con 18 millones de residentes (según el censo del año 2000), lo que no es demasiado en comparación con los mil billones de habitantes de la capital galáctica. Sin embargo, desde mediados del siglo $\mathrm{XX}$, los procesos de expansión urbana que caracterizan la antigua misión jesuita fundada en 1554 recuerdan de manera extraña los que están descritos y denunciados por los autores de Star Wars.

Ahora bien, el paralelo no se detiene allí: después de Nueva York, se considera que São Paulo dispone del parque de helicópteros más grande del mundo. Sin lugar a dudas esta es la forma de garantizar el desplazamiento rápido y seguro de las élites locales, que no quieren arriesgarse en las calles perpetuamente congestionadas de una ciudad donde las tasas de criminalidad son altísimas y nutren el sentimiento de miedo de los habitantes. En el cielo se puede admirar un verdadero ballet aéreo muy parecido a los flujos de airspeeders que giran entre las torres de Coruscant. Los edificios más recientes están dotados con helipuertos privados que permiten a unos cuantos privilegiados (cada vez más numerosos) vivir en la ciudad de manera completamente desconectada, pasando de un lugar cerrado a otro también cerrado (residencia, trabajo, ocio), evitando pasar por los espacios públicos abandonados a los ciudadanos comunes y corrientes. Ya en 1930, cuando Paul Morand hacía el retrato de los rascacielos de Nueva York, profetizaba que una nueva revolución de los transportes iba a transformar en breve tiempo nuestros modos de vida: "sin techos, coronados con terrazas, parecen esperar globos rígidos, helicópteros, los hombres alados del futuro" (Morand, 1930).

Esta evolución de la sociedad posmoderna que conduce a la desaparición de los espacios de intercambio y encuentro, que son la calle, los parques y las plazas induce a los autores de Star Wars a entablar una relación estrecha entre la morfología de la ciudad y las formas de sociabilidad que ésta favorece o prohíbe, entre los paisajes urbanos y el pensamiento político que éstos simbolizan, reproducen y perpetúan. La reacción de los recién llegados sobre el planeta expresa la ambivalencia de los sentimientos que inspiran estos paisajes urba- nos desproporcionados: "Bria miró a su alrededor, a la vez maravillada y aterrorizada. Estaba rodeada por fachadas inmensas, perteneciendo a torres tan grandes que debía torcerse el cuello para percibir su cumbre" (Crispin, 2000: p. 271). El comportamiento de la joven Bria cuando se adentra por primera vez en Coruscant, recuerda la actitud de los europeos de la primera mitad del siglo XX, cuando descubrían la civilización urbana estadounidense, con todas sus audacias arquitectónicas y su carácter a la vez innovador y amenazador. En 1930, Georges Duhamel se declaraba disgustado por el paisaje urbano de Chicago (“ $¡$ Chicago! $¡ \mathrm{La}$ ciudad tumor! ¡La ciudad cáncer!”), con sus edificios descomunales, sus calles similares a trincheras cortadas en una masa de hormigón y acero, sus mares de coches apestando (Duhamel, 2003: p. 72). Sin embargo, en la misma época, Paul Morand prefería destacar la imagen de una sociedad joven y pujante que expresaba con su arquitectura la fuerza de sus ideas religiosas y de su crecimiento económico: "el alma de estos edificios es el éxito: no son sino el tabernáculo del triunfo; triunfo financiero, tan dulce para el Dios de los Puritanos como una oración. Como la flecha de una catedral, se extienden hacia el cielo en un empuje a la vez místico y económico" (Morand, 1930). A su juicio, Nueva York, ciudad del futuro, anunciaba no solo nuevos modos de vida sino también la llegada de hombres nuevos.

Como se puede ver en las películas de la segunda trilogía, los edificios de Coruscant presentan una enorme variedad de estructuras, formas y fachadas que dan a la ciudad un carácter a la vez heteróclito y cosmopolita. Con el propósito de acentuar la impresión de exotismo que permitirá llevar al lector hacia mundos extraños sin cortarlo enteramente de sus raíces. Los autores de la saga utilizan un método conocido desde hace tiempo: la alusión a modelos arquitectónicos cuyo nombre entró en el vocabulario coloquial, pero que autorizan todas las interpretaciones, todos los sueños urbanísticos. Es la técnica utilizada por Michael Reaves en La sombra del cazador: "Prácticamente toda la superficie del globo estaba cubierta -puesto que se habían desecado o desviado los mares y los océanos a través de extensas cavernas subterráneas, millares de generaciones antes de la fecha- por una metrópolis con múltiples niveles constituidos de 
torres, ziggurats, palacios, cúpulas y alminares" (Reaves, 2001: p. 28). Los términos de ziggurats y de alminares permiten vincular la arquitectura extraterrestre de Coruscant con las grandes civilizaciones más o menos conocidas, pero que siguen siendo muy distantes, tanto en el tiempo como en el espacio, del público estadounidense.

Si los alminares recuerdan el mundo musulmán antiguo y contemporáneo, los ziggurats hacen referencia a los albores de nuestra civilización y a los principios del urbanismo. En efecto, las famosas pirámides con escalones de Mesopotamia son el símbolo de las primeras ciudades construidas por el hombre. Ocupan esos edificios un lugar destacado en nuestro imaginario colectivo porque inspiraron el mito de la torre de Babel, que también sirvió de modelo para el planeta-ciudad de Coruscant caracterizado por su arquitectura vertical, la centralización del poder y el uso de una lengua universal (the Basic).

Siguiendo el mismo camino, Paul Morand distinguía también pirámides prehispánicas en medio de los edificios dispares que caracterizan el urbanismo de Nueva York: “¡Los rascacielos! Allí, unos son mujeres y otros hombres; los unos parecen templos al Sol, los otros recuerdan la pirámide azteca de la Luna" (Morand, 1930). De la misma manera, en el Blade Runner de Ridley Scott, el paisaje urbano de Los Angeles del futuro está dominado por una gigantesca construcción que sirve de refugio a Tyrell, el hombre más poderoso de la ciudad: este edificio impresionante no es sino una extrapolación arquitectónica de la pirámide del Sol de Teotihuacán. En cuanto al nuevo templo Jedi construido sobre el planeta Ossus, después de la guerra de los Yuzzhan Vong ${ }^{4}$, su estilo se inspira directamente de la arquitectura maya, como lo reconoce la dibujante de la historieta Legacy: "Para el templo Jedi, yo quería evocar un antiguo templo maya, pero con plataformas de aterrizaje. También añadí zonas cubiertas de acero transparente que reflejan el cielo y los alrededores. Creo que los

Esta nueva guerra galáctica ocurre 25 años después del año 0 de la cronología Star Wars, que corresponde a la destrucción de la primera Estrella Negra (A New Hope, 1977).
Jedi arreglaron un jardín de meditación abajo" (Lucasfilm Magazine, 2006: p. 17). ${ }^{5}$

Ahora bien, las figuras de estilo utilizadas por los autores de ciencia ficción no son muy diferentes de las que encontramos bajo la pluma de los exploradores o conquistadores del siglo XVI. Por varios motivos, el descubrimiento del Nuevo Mundo fue para los europeos un choque tan violento como lo sería para nosotros el descubrimiento de un nuevo planeta habitado. Los relatos de los conquistadores parecían tan extraordinarios que suscitaban a menudo las dudas y las burlas de los unos, aunque causaban la admiración y el respeto de los otros. Bernal Díaz del Castillo reconoce así en sus memorias, que él mismo ni siquiera podía creer lo que veía con sus propios ojos y se pensaba trasladado en uno de esos libros de caballerías donde la parte de lo maravilloso triunfa siempre sobre la realidad (Díaz del Castillo, 1983: p. 159). Para tratar de proponer una imagen aceptable de las ciudades amerindias, Cortés recurrió a las mismas estratagemas estilísticas que los autores de la saga Star Wars, convirtiendo las pirámides aztecas en mezquitas y las torres de los templos en alminares. En su segunda carta a Carlos V, describía así la ciudad de Churultecal: "certifico a vuestra alteza que yo conté desde una mezquita cuatrocientas treinta y tantas torres en la dicha ciudad, y todas son de mezquitas" (Cortés, 1983: p. 45). Más adelante, Cortés dice que en México se encuentran "muchas mezquitas" pero que "no hay lengua humana que sepa explicar la grandeza y particularidades" de la principal (el templo mayor) (Cortés, 1983: p. 64). De la misma manera, la primera gran ciudad encontrada por los españoles en las costas de Yucatán fue rebautizada como El Gran El Cairo, con el propósito de dar a entender su tamaño y riqueza a los que se habían quedado en la península.

La referencia a la civilización del otro, a la cultura del extranjero conocido pero alejado, permite dar un sello de autenticidad a descripciones que, sin esta precaución oratoria o literaria, podrían parecer puras fantasías.

\footnotetext{
$5 \quad$ Se puede notar al respecto que en el episodio IV de la saga (A New Hope, 1977), la base rebelde de Yavin IV no es sino la ciudad maya de Tikal (Guatemala).
} 


\section{“Maquiladoras” galácticas}

Al describir la ciudad global de Coruscant, los autores de la saga Star Wars no se limitan a hacer el retrato de una megalópolis futurista cuyos paisajes urbanos están dominados por una serie de edificios notables, símbolos de una civilización pujante: exponen claramente los mecanismos de funcionamiento de una sociedad que ya no necesita producir bienes materiales para afirmar su potencia, sino todo lo contrario. Simple extrapolación de una evolución en curso, pero empujada hasta su extremo, el planeta-ciudad de Trantor descrito por Asimov a principios de los años 1950 ya respondía perfectamente a las normas de la ciudad global, descrita posteriormente por Saskia Sassen ${ }^{6}$ : "El planeta sólo tenía una función, la administración. Sólo un objetivo, el Gobierno. Sólo producía un único producto manufacturado, la ley" (Asimov, 1999: p. 63). De la misma manera, la Coruscant de Star Wars es antes que todo un centro político que produce en continuo el arsenal legislativo y el marco jurídico destinados a garantizar la dirección de un mundo globalizado. En este sentido, al igual que cualquier otra ciudad global, la capital imperial basa su prosperidad económica y su potencia política sobre los servicios de alto nivel. Salvo las instalaciones destinadas a generar energía y a eliminar los residuos urbanos, se cuentan pocos centros de producción, tales como los astilleros dedicados a la reparación de las naves estelares (Allston, 2000: p. 15) o algunas fábricas que, por razones estratégicas, no han sido trasladadas hacia planetas periféricos ${ }^{7}$. En un sistema eco-

\footnotetext{
Como lo destaca Saskia Sassen, la ciudad global no es solamente un polo de decisión estratégico sino también un lugar donde la sociedad dominante produce bienes no materiales, en particular los servicios destinados a las empresas multinacionales, en ámbitos tan variados como los seguros, el derecho, la contabilidad, la fiscalidad, la publicidad o las relaciones públicas. Es allí también que están diseñados los nuevos instrumentos políticos, técnicos y financieros que permiten la instauración de una "buena gobernabilidad" mundializada. Estos dos sectores conjuntamente forman el corazón de la nueva economía urbana (Sassen, 1991).
}

Sin embargo, para los autores de ciencia ficción como para sus lectores, es difícil aceptar la idea de una ciudad gigante desprovista de centros industriales. La gran aglomeración sigue siendo el lugar por excelencia de la producción manufacturera, a la vez símbolo de potencia económica y fuente inagotable de molestias y contaminación. En nuestros imaginarios colectivos, la tasa de dióxido de carbono expulsado nómico que se inspira en nuestra actual división internacional del trabajo, son planetas-talleres con actividades especializadas las que abastecen los principales mercados consumidores de la galaxia, es decir mundos enteros que se tornaron incapaces de satisfacer sus propias necesidades. Para los empresarios de Star Wars, como en toda economía liberal, la mejor manera de reducir los costos y aumentar los beneficios es deslocalizando las unidades de producción hacia zonas que gozan de ventajas comparativas innegables: una mano de obra cualificada y mal pagada, una legislación local no apremiante (derecho del trabajo, fiscalidad), excelentes condiciones de transporte... Como lo dice James Luceno para explicar la desaparición de las manufacturas de Coruscant: "Los Works han sido una zona industrial dinámica hasta que el crecimiento de los costos desencadenara el traslado de la producción de vehículos espaciales, de los robots y de los materiales de construcción, hacia otros mundos" (Luceno, 2005: p. 174). En Labyrinth of Evil, su descripción de la antigua zona industrial no es sino una evocación disfrazada de los antiguos espacios industriales contaminados (brownfields) que salpican el tejido urbano de las grandes ciudades del cinturón de herrumbre estadounidense, al sur de los Grandes Lagos. Sobre varios centenares de kilómetros cuadrados se extiende un paisaje caótico de donde surgen los esqueletos ennegrecidos de antiguas manufacturas abandonadas desde hace varias generaciones. Los productos químicos utilizados en la época de máximo rendimiento de las manufacturas siguen envenenando el aire con el ácido que se estanca alrededor de los altos hornos apagados. James Luceno indica que en vano se intentó hacer desaparecer estos vestigios del pasado industrial del planeta, tal como se hace hoy en día en los Estados Unidos o en Europa para fomentar la reconversión de las zonas abandonadas por las empresas. ${ }^{8} \mathrm{De}$

a la atmósfera sigue apareciendo como un equivalente de los índices bursátiles: cuanto más elevado es el contenido, tanto más sube la nación en la jerarquía del desarrollo. Es así como varios planos de la película El ataque de los clones nos enseñan las formidables instalaciones industriales de Coruscant, ahogadas en una atmósfera rojiza. Las fábricas son dominadas por chimeneas gigantescas, de dónde se escapan nubes de humo negro, imagen tradicional del triunfo de la mecanización.

8 En los EE-UU, el Brownfields Cleanup and Redevelopment Program ha sido creado en 1995 como programa de la 
manera irónica, denuncia las prácticas dudosas de promotores codiciosos y especialistas de la renovación urbana (urban renewalists) que intentaron acelerar los procesos de degradación de los edificios minados por las emanaciones de ácido, introduciendo en la zona contaminada "ácaros de piedra", "limazas de hormigón" y "gusanos de canalización". Su objetivo era eliminar a menor costo las gigantescas instalaciones industriales, abandonadas con el propósito de desarrollar programas inmobiliarios muy lucrativos (Luceno, 2005: p. 2008).

El planeta Kuat forma parte de los beneficiarios de este proceso de globalización que afectó el conjunto de la galaxia. Bajo la Antigua República se convirtió en un gigantesco centro de producción de vehículos interestelares. Reuniendo varios millones de obreros en instalaciones situadas en órbita del planeta, los Astilleros Kuat (CNK) se especializaron en la fabricación de unidades de enorme calado, en particular para el sector militar (destructores estelares de clase imperial). Del mismo modo, Bilbringi se convirtió en el centro de producción de cazadores y naves de guerra, más importante del Imperio, gracias a las instalaciones industriales agrupadas en el seno de las unidades de producción muy bien defendidas (X-7 Factory Estaciones).

Con el fin de limitar las molestias relacionadas con la producción manufacturera (ruido, congestión, contaminación...), las actividades más sensibles han sido trasladadas hacia planetas cuyos ecosistemas padecen desde aquel entonces las consecuencias de un desarrollo industrial devastador. Es así como el sistema de Fondor fue trastornado por los talleres de construcción que aprovecharon sin vergüenza los minerales extraídos no solo del subsuelo, sino tambien de sus lunas y asteroides: "Las grandes sociedades que dominaban a Bilbringi, Kuat, Sluis Van y a los demás centros de astilleros hacían un esfuerzo mínimo para preservar el medio ambiente, en cambio nada similar había sido previsto en Fondor" (Luceno,

Agencia para la protección del medio ambiente, con el fin de apoyar la acción de los Estados e instituciones públicas o privadas que quieren limpiar y revitalizar los terrenos contaminados por antiguos polos industriales (en 2006, 450.000 zonas de este tipo estaban registradas).
2001: p. 268). De la misma manera, una explotación industrial sin freno hizo del planeta Duro un extenso desierto, del que sus habitantes huyeron para refugiarse en ciudades orbitales. Se intentaron algunas experiencias para sanear las ciénagas, purificar los suelos y volver el aire respirable, pero los resultados han sido limitados por falta de medios técnicos y recursos financieros. Por esta razón la princesa Leia, enviada por el gobierno republicano para fomentar la regeneración del planeta, ha sido transformada en portavoz de los grupos de presión ecologistas estadounidenses. Sobre este planeta muerto, debe pelear de manera continua contra una administración central que se niega a concederle los medios necesarios para llevar a cabo su programa (Tyers, 2001: p. 42).

En el imaginario de los lectores estadounidenses, la situación de Fondor o Duro refleja cierta realidad (en gran parte fantasmagórica). En efecto, para describir el sistema económico dominante en la galaxia Star Wars, los autores escogidos por Lucasbooks no hacen más que mirar hacia la zona fronteriza entre México y Estados Unidos donde la industria maquiladora se ha desarrollado de manera desmedida desde mediados de los años sesenta. ${ }^{9}$ Al Norte, un establecimiento reúne las funciones de administración y gestión (es el papel atribuido a Coruscant). Al sur (el equivalente geopolítico y económico de Fondor), la planta de ensamblaje ve su papel limitado a funciones productivas centradas en el trabajo manual, aprovechando un marco jurídico y social más acogedor que en los Estados Unidos. No es una casualidad si, según una encuesta realizada por El Colegio de Frontera Norte a principios de los años 1990, el 10\% de las empresas instaladas en la zona fronteriza reconocieran que fueron atraídas por el carácter más flexible de la legislación mexicana sobre el medio ambiente. En total, más de un cuarto de las empresas maquiladoras consideraban este capítulo como fundamental para justificar su deslocalización al sur del límite internacional.

\footnotetext{
9 Aunque la capital de la industria maquiladora sigue siendo Ciudad Juárez (217.000 empleados y 291 establecimientos en 2005), la Baja California ocupa en este sistema un papel esencial, puesto que Tijuana, Mexicali y Tecate cuentan entre las ciudades mexicanas mejor equipadas con respectivamente 574, 135 y 115 fábricas instaladas en su territorio.
} 
Las novelas Star Wars usan los mismos argumentos para explicar la instalación de las industrias más contaminantes sobre planetas alejados de Coruscant: el alejamiento se presenta pues como una solución adecuada en el marco de una sociedad caracterizada por el síndrome NIMBY (Not In My Backyard). Es así como, en Renacimiento, novela del ciclo El Nuevo Orden Jedi, los pilotos de la Nueva República descubren que el planeta Eriadu padece una atmósfera contaminada por vapores de hidrocarburo, azufre, ozono y amoníaco. Los paisajes urbanos son caracterizados por inmensos rascacielos industriales que se destacan sobre un cielo amarillo pálido, obscurecido por los humos de las fábricas. La explicación de este desastre ecológico es dada por Corran Horn, jefe del grupo encargado de combatir al invasor Yuuzhan Vong: "Aquí, se fabrican los productos al menor costo con menosprecio del medio ambiente. El olor es un subproducto de la industria" (Keyes, 2002: p. 101). Se entiende fácilmente pues, por qué la cuestión medioambiental ocupa un lugar tan importante en esta galaxia lejana que refleja todas las inquietudes y preocupaciones de la sociedad estadounidense. Para un habitante de Austin (Texas) o Phoenix (Arizona), los planetas de Fondor y Duro no se sitúan a años luz de su domicilio: están al alcance de la mano y tienen por nombre Matamoros (Tamaulipas) o Nogales (Sonora). De hecho, Kathy Tyers, a quien se deben las descripciones apocalípticas del planeta Duro, es originario de Largo Beach, en California, Estado fronterizo con México. Michael Reaves nació en San Bernardino, a 40 kilómetros al Oeste de Los Angeles. En cuanto a James Luceno, antiguo carpintero de profesión, él reconoce que cruza a menudo la frontera para buscar del otro lado sus fuentes de inspiración (Luceno, s.f.).

Pero más grave aún es para los autores de Star Wars, la presencia de millones de trabajadores en búsqueda de distracciones, después de tantas horas de trabajo, que tiene por consecuencia directa la creación de instituciones y establecimientos que transforman a los planetas-talleres en lugares peligrosos para la salvación del alma. La destrucción del medio natural se duplica pues de un verdadero problema moral -tema especialmente importante para autores estadounidenses siempre preocupados por las cuestiones éticas y religiosas-. Así pues,
Kathy Tyers, autor de Punto de equilibrio, forma parte de la asociación de los escritores cristianos (Christian Writers Guild) y da a menudo conferencias públicas sobre temas religiosos. Al denunciar esta situación, los autores de ciencia ficción hacen referencia directa o indirectamente al lado mexicano de la frontera, donde la profusión de bares, casinos, hoteles y prostíbulos nutre la imagen despreciada de un México poblado de prostitutas y narcotraficantes. Se puede pues considerar que los tristes antros de Fondor no son más que una transposición literaria de las cantinas de Mexicali o Nuevo Laredo.

\section{La ciudad y sus peligros}

En la ciencia ficción estadounidense, la hiperconcentración de las actividades industriales y comerciales, las densidades de población juzgadas como excesivas y la desaparición del vínculo privilegiado establecido desde los orígenes entre el hombre y la naturaleza, se oponen a una ideología dominante cuyas raíces se encuentran en las novelas naturalistas de H. J. Thoreau (2004) o en los poemas y ensayos de Rafael W. Emerson (Oliver, 2000). Esta visión negativa del mundo urbano no es una peculiaridad de la filosofía estadounidense, como lo mostró Joëlle Salomon Cavin en su obra La ville mal aimée (La ciudad mal amada), donde se observa que las sociedades occidentales despreciaron a menudo las grandes aglomeraciones, prefiriendo idealizar las formas de vida rurales, y dotaron de todas las virtudes a los habitantes del campo (Salomon Cavin, 2005). Al hacer hincapié en la amplitud y la diversidad de los problemas encontrados para administrar la capital galáctica, los autores de Star Wars no hacen más que difundir un discurso pesimista sobre el futuro de nuestras propias ciudades: de la megalópolis a la monstruopolis el paso es muy fácil de cruzar, sobre todo cuando la realidad supera a la ciencia ficción...

Así pues, en Coruscant, como en las ciudades que le sirven de modelo, la saturación del tráfico causa un aumento vertiginoso de la contaminación atmosférica: "Los embotellamientos bloqueaban el cielo de Coruscant. Los flujos de vehículos avanzaban lentamente entre las volutas de niebla cargadas de contaminación" (Salvatore, 2002: p. 
67). Para dar cuenta de una situación idéntica, Claude Bataillon y Louis Panabière habían rebautizado a la capital mexicana como Smogopolis, perpetuamente envuelta de una nube amarillenta que escondían las montañas vecinas. Según los estudios realizados a principios de los años 1980, la contaminación del aire había alcanzado en ese momento un punto que se suponía sin retorno: los gases de los escapes y los humos eliminados por las chimeneas y las fábricas, quebrantaban la salud física y mental de los habitantes más expuestos y más débiles: "las fábricas de aceite para jabón y de alimentos para animales escupen todos los días, a las $7 \mathrm{~h}, 12 \mathrm{~h}$ y $24 \mathrm{~h}$ gases tóxicos que afectan a la cabeza y al estómago, causan la caída del cabello" (Bataillon \& Panabière, 1988: p. 37). Para William Sandell, encargado de la producción durante el rodaje de Total Recall (realizado en los estudios de Churubusco de la Ciudad de México, en 1989), vivir en esta ciudad saturada de gases de escapes y humos de fábrica, "es un poco como vivir en la capital mundial de la contaminación. Respirar el aire de México, es como fumar cuarenta cigarrillos al día" (Verhoeven, 2003).

En la saga se constata que, dado que el medio ambiente original de Coruscant desapareció casi por completo, sólo en museos o en holo-zoológicos los niños pueden admirar los animales o las plantas que nunca tendrán la oportunidad de ver en realidad porque sus padres eligieron vivir en la capital galáctica. Para ofrecerles una idea de las maravillas del mundo natural, un inmenso jardín botánico ha sido instalado en la cumbre de un rascacielos. Además de especies vegetales importadas de todo el universo conocido, se cultivan plantas y flores que desaparecieron de la superficie del planeta centenares de generaciones antes. Kevin J. Anderson dio a este terrarium gigantesco el nombre de Skydome porque quería recordar el famoso Biodôme de Montreal, que reúne bajo una gigantesca cúpula de vidrio y acero ${ }^{10}$ cuatro grandes ecosistemas naturales, que se ponen al alcance de todos los habitantes de la ciudad: la selva del trópico húmedo; el bosque típico de la región del río San Lorenzo que cambia de aspecto según las estaciones; el ecosistema marino del

10 Se trata del velódromo construido para los Juegos olímpicos de 1976. estuario y Golfo del San Lorenzo y los mundos polares del Ártico y la Antártica (Estébanez, 2006: pp. 708-731). Abierto en junio de 1992 (es decir dos años antes de la publicación de Jedi Search en los Estados Unidos), el Biodôme se presenta de manera oficial como un oasis en el corazón de la ciudad. En este sentido, desempeña en Montréal el mismo papel que el Skydome en Coruscant: por solo unos pocos dólares, el visitante puede hacer un paseo educativo que lo lleva de un punto al otro del continente americano sin tener que dejar su domicilio.

Sin embargo, entre todos los peligros que amenazan las ciudades de ciencia ficción y juegan un papel determinante en el imaginario de sus habitantes, uno pesa más que los demás: la inseguridad. En efecto, la yuxtaposición en un mismo lugar de diferentes etnias y clases sociales con intereses diversos y a veces contrarios, se presenta como una fuente de tensiones permanentes que causan el aumento de la criminalidad, exactamente como en las grandes ciudades estadounidenses o latinoamericanas que sirven de modelo a los cineastas y novelistas.

$\mathrm{Al}$ respecto, unos escritores no dudan en trasladar hacia un futuro inmediato situaciones muy conocidas en nuestras ciudades, y ni siquiera sienten la necesidad de cambiar los nombres de los barrios donde viven sus héroes. Es el caso del francés Fabrice Colin, que presenta de manera muy clara las profundas disparidades socioeconómicas de Río de Janeiro del año 2020, cuando las autoridades locales dejan en manos de androides el mantenimiento del orden público para eliminar a los parásitos sociales y a los delincuentes. Su personaje principal, un joven huérfano bautizado como Tiago Pericles Edelson, trabaja para una banda de narcotraficantes y vive con su abuelo en una barraca miserable de Rocinha, "la favela más grande de Brasil, acunada entre dos brazos de la montaña, bajando la colina como un derrame de casas cúbicas, una marea sin fin". De manera cínica, Fabrice Colin destaca que los asesinatos y el tráfico de drogas no le molestan al Gobierno siempre y cuando las actividades ilegales permanezcan limitadas al territorio de la favela. Al contrario de este mundo de pobreza y desesperación, se encuentran los barrios elegantes, tal como la "rua 
Viconde de Pirajá que desborda de tiendas, galerías de arte y restaurantes fuera de todos los precios" (Colín, 2006: p. 31).

Con El pequeño mundo, europeo, poético y violento, J.D. Morvan y Toru Terada no hacen más que reproducir las divisiones socioespaciales que caracterizan a las grandes metrópolis de los países en vías de desarrollo. Cuando los ricos del futuro viven en barrios cerrados y protegidos, los pobres están confinados en un gigantesco barrio de chabolas que empapela las paredes casi verticales del pozo donde se acumulan los residuos de la ciudad moderna. El paisaje pintado por Toru Terada para ilustrar este universo de violencia y miseria, recuerda de manera extraña las grandes favelas de Río de Janeiro. Perseguidos por escuadrones de la muerte financiados por la alta burguesía y más o menos tolerados por la policía oficial, los niños de las calles intentan sobrevivir multiplicando los tráficos más sórdidos: "vuelo, prostitución y tráfico de drogas son aquí los únicos medios para ganar la vida. Los niños comienzan temprano en el negocio y conforme pasa el tiempo, tienen menos escrúpulos" (Terada \& Movan, 2005: p. 9).

Debido a que la saga Star Wars anuncia y también denuncia los problemas planteados por el desarrollo incontrolable de las metrópolis modernas, no es asombroso constatar que la delincuencia, bajo todas sus formas, se presenta como un constituyente de la vida diaria. En Estados Unidos y América Latina, los telespectadores siguen con un interés creciente programas que permiten asistir casi en directo a escenas de brutalidad y crimen (ataques de banco o tiendas comerciales, secuestros, ajustes de cuentas, persecuciones en las calles...), todo bajo el pretexto de criticar las fallas de la administración central y la clemencia supuesta de los tribunales. En Prime Time, estos programas reúnen millones de telespectadores fascinados por una violencia institucionalizada que tiene el sabor del reportaje periodístico y nutre los sentimientos colectivos de paranoia, al conformar una geografía del miedo basada en la estigmatización de lugares específicos. Como lo decía al respecto Susana Rotker: "La sensación del miedo es tan inexpresable como la del dolor para los seres humanos y, sin embargo, hay lugares donde es una experiencia cotidiana" (Rotker, 2000: p. 9).
En México, por ejemplo, es el barrio de Tepito uno de los que sintetiza todos los miedos de los ciudadanos ordinarios, como lo recuerda Rodrigo Fresán de manera irónica en su novela: "Tepito es la capital mexicana del contrabando rápido y la muerte aún más expeditiva" (Fresán, 2006: p. 434). En Bogotá, el mismo papel era atribuido a la Calle del Cartucho, ubicada a cuatro manzanas del centro histórico y considerada por los habitantes de la capital colombiana como el lugar más peligroso de su ciudad. Como lo decía un residente de la localidad de Usaquén, influenciado por lo que había visto en la televisión y leído en los periódicos: "He oído y he visto por la televisión que allá hay de todo, hace poco leí en la prensa que un señor se fue del país porque un taxista trató de violar a la hija y como ella no se dejó, el tipo se la llevó a El Cartucho y la tiró allá, en donde hicieron de todo con la muchacha" (Niño Murcía et al., 1998: p. 104). Lo mismo ocurre en el barrio San Antonio en la ciudad de Guatemala (la zona 6), donde las pandillas aprovechan los barrancos aledaños para esconderse y agilizan las operaciones de los narcotraficantes, que aterrorizan a los vecinos, sin que se puedan conseguir datos estadísticos confiables en relación con los verdaderos niveles de criminalidad de la zona.

Los personajes de las novelas Star Wars comprueban pues la misma angustia que sus lectores al arriesgarse en las calles de una ciudad transformada en trampa para los transeúntes: "Mahwi Lihnn examinaba los pasos y las callejuelas del barrio, buscando la cantina del Dewback. Esta zona de Coruscant no le daba miedo. ${ }^{11}$ Las calles de la superficie sólo eran pasillos tortuosos y estrechos callejones sin salida, infestados por unos sinvergüenzas listos para asaltar a las presas débiles" (Reaves, 2001: p. 97). La evocación recurrente de las zonas bajas de la capital galáctica como lugares peligrosos, en donde el temor a la agresión ha suplantado el deseo del encuentro, participa en la instauración de un imaginario colectivo basado en el miedo al otro y en la lógica de la violencia diaria. 
Es así como, al llegar a las profundidades del planeta-ciudad, el joven Han Solo debe enfrentar a un grupo de jóvenes que pretenden asaltarlo: "Cuando salió del elevador, las calles eran siniestras y húmedas. Una pandilla de adolescentes avanzó hacia Han" (Crispín, 1997: p. 273). De manera por cierto ridícula, pero reveladora de los estereotipos conllevados por los streetgangs, el jefe de la banda que ataca a Han Solo no es sino un joven de piel oscura, con el cabello negro y engominado, prototipo del joven chicano cuyos padres cruzaron clandestinamente la frontera entre México y los Estados Unidos (Crispín, 1997: p. 273). Es el digno representante de estos gangs étnicos que agrupan Negros o Latinos y asustan a la clase media estadounidense, compuesta tradicionalmente de WASPS (White Anglosaxon Protestants). En 2002, en el condado de Los Ángeles, las estadísticas oficiales registraban a más de 1.300 streetgangs que congregaban a más de 150.000 miembros. Las cifras son suficientemente altas para mantener una verdadera psicosis en los habitantes de la metrópolis californiana (Alonso, s.f.). Según los últimos datos disponibles, en diciembre de 2005 la policía contabilizaba a 463 pandillas (de las cuales 246 eran hispánicas) y a 38.974 afiliados (de los que 21.790 eran latinos) solo para el municipio de Los Ángeles. Por sí solo, 18th Street Gang (Mara 18), reuniría a casi 20.000 jóvenes distribuidos en varias decenas de subgrupos activos en el centro y en la mayoría de los barrios de la megalópolis.

La relación joven hispánico/miembro de un streetgang es tanto más fuerte cuanto los vínculos tejidos por los delincuentes ubicados a ambos lados de la frontera terminaron por imponer el modelo criminal estadounidense en las grandes ciudades mexicanas. Se sustituyeron pues a las antiguas estructuras (gavillas, palomillas, pandillas) que reunían tradicionalmente a los jóvenes de los barrios populares, cuando se importaron los métodos y prácticas del otro lado: prendas de vestir, tatuajes, uso de distintas drogas, violencia ritual -y también lenguas cifradas y músicas mestizas. En Centroamérica, la violencia de las Maras se tornó incontrolable. Según la policía guatemalteca, la Mara 18 y la Mara Salvatrucha o MS-13 (ambas nacidas en Los Ángeles) agruparían a más de 160.000 jóvenes de 12 a 25 años, responsables de la mayoría de los crímenes y delitos registrados en el territorio nacional. Las confrontaciones entre las dos familias se concluyen a menudo en verdaderas matanzas donde las bajas pueden contarse por decenas.

Para denunciar esta evolución hacia un modelo de sociedad urbana cada vez más violenta, Richard Kadrey escogió como héroe para su novela Metrophage a un joven narcotraficante, Jonny Qabbala, que trata de sobrevivir en Los Ángeles del futuro, fragmentada entre las fuerzas del Committee for Public Health y los streetgangs que se disputan el jugoso mercado negro, no solo de las drogas sino también de la energía y la comida (Kadrey, 1988). Entre los grupos de delincuentes más destacados encontramos a los Lizard Imperials (con sus botas de piel de serpiente), los Zombie Analytics, los Croakers, los Yakuza Rebels, los Gypsy Titans y los Naginata Sisters, que acogen a chicas sin vergüenza ni piedad — sin olvidar a Los Santos Atómicos (cuyo nombre aparece escrito en español en la edición original).

En realidad, poco importa el lugar en el que transcurren las situaciones, poco importa la época: es la ciudad moderna en sí misma, su arquitectura, su organización espacial, sus paisajes que fomentan y nutren la delincuencia. Por consiguiente, todos los autores del universo Star Wars coinciden para considerar que el urbanismo de Coruscant por sí mismo es criminógeno: "con sus innumerables barrancos oscuros, sus terrazas que dominan precipicios, sus numerosos rincones, sus parapetos sobresalientes y la letanía de lugares que permitían escaparse a los ojos y a la vista de todos, Coruscant era una invitación al crimen y a la corrupción. Su propia geografía inspiraba el misterio" (Luceno, 2002: p. 156). Todos estos espacios apartados y escondidos, todas estas zonas de sombra, hacen de la gran ciudad un refugio para los delincuentes que quieren disimular sus actividades criminales. Por esta razón uno de los desafíos del urbanismo contemporáneo en busca de seguridad consiste en abrir los espacios, para favorecer la puesta en perspectiva de los espacios públicos. Así sería posible permitir a cada uno observar todo lo que está pasando en su alrededor, a fin de garantizar una vigilancia de tipo comunitaria en todos los lugares (Garnier, 1999). De cierto modo, también es el punto de vista de los arquitectos y urbanistas 
estadounidenses del movimiento New Urbanism, que quieren regresar a una ciudad neo-tradicional y devolver a los espacios públicos el estatuto que perdieron en el transcurso del siglo XX: "Streets and squares should be safe, comfortable, and interesting to the pedestrian. Properly configured, they encourage walking and enable neighbors to know each other and protect their communities" (CNU, s.f.).

En este sentido, la ciencia ficción hace hincapié en una de las amenazas que, en nuestras representaciones colectivas, hipoteca el futuro de las ciudades americanas: la desaparición progresiva de los espacios públicos y el fin de la ciudad como órgano político. En Coruscant, las calles desaparecieron de la superficie del planeta. Sólo están presentes en los bajos fondos de la megalópolis, donde gobiernan los criminales y donde los pobres se esconden en sus tugurios. En las alturas, los lugares de paso se limitan a pasarelas tendidas entre los rascacielos. Esto limita drásticamente las posibilidades de circulación, aunque garantice un máximo de paz y seguridad para los habitantes. Ahora bien, como ya lo decía Jane Jacobs en 1961, las calles y las plazas, es decir los lugares donde los habitantes pueden caminar, son la esencia de la vida ciudadana y la urbanidad: "las calles y sus aceras son los principales lugares públicos de una ciudad, sus órganos más vitales. ¿Qué es lo primero que nos viene a la mente al pensar en una ciudad? Sus calles. Cuando las calles de una ciudad ofrecen interés, la ciudad entera ofrece interés; cuando presentan un aspecto triste, toda la ciudad parece triste" (Jacobs, 1967: p. 33). Las advertencias que lanzó en su tiempo para denunciar un urbanismo tecnócrata e inhumano, destructor de las formas urbanas que propician al encuentro (los barrios tradicionales, considerados por los especialistas del ordenamiento territorial y los promotores inmobiliarios, como obstáculos a la modernidad), influyeron sin duda en la visión pesimista de los autores, no sólo de Star Wars sino también de casi todas las obras de ciencia ficción relacionadas con la temática de la ciudad.

\section{Conclusión: regreso al gueto y muerte de la ciudad}

Una forma de mitigar el riesgo social y luchar contra el miedo puede ser la instauración de un orden político más estricto, es decir un orden basado en un control policial más eficaz. La nostalgia de un tiempo en que las autoridades sabían cómo someter a los rebeldes o a los delincuentes puede seducir a una parte de la población, asustada por los excesos cometidos en sistemas democráticos juzgados como demasiado permisivos. Así, se abren las puertas a los discursos populistas y reaccionarios como aquél que utiliza Brakiss para atraer al joven Zekk hacia la Academia de la Sombra, un grupo fascista que quiere acabar con la República y regresar a un sistema político autoritario: "el imperio no conocía el desorden. Había oportunidades de éxito. En aquel entonces las Maras no florecían en las calles de Coruscant" (Anderson \& Moesta, 1997: p. 109). Son los mismos discursos que se usan cada vez más en las campañas electorales a fin de ganar los votos de los electores aterrorizados por el crecimiento de la violencia diaria presentada en los noticieros y los periódicos. Por ejemplo, el candidato del Partido de la Revolución Democrática a la elección presidencial de México en 2006, Andrés Manuel López Obrador, cuando estaba a cargo del Gobierno de la Ciudad de México, no dudó en solicitar la ayuda del antiguo alcalde de New York, Rudolph Giulani, para diseñar un programa de tolerancia cero hacia la delincuencia en la capital federal ${ }^{12}$.

Para los que no reconocen que la solución política o policial sea la correcta salida del problema, incluso al precio de una restricción drástica de las libertades individuales, queda una opción: el encerramiento en barrios cerrados, fraccionamientos y condominios cerrados. Es el modelo urbano elegido por los habitantes de Coruscant, quienes para huir de los peligros reales o imaginarios que los acechan en la calle, prefieren refugiarse en edificios cerrados como fortines cercados por bárbaros. El modelo de las gated communities aparece entonces como el resultado de una larga historia urbana caracterizada por la imposibilidad de convivencia en un mismo territorio de clases sociales enemigas o enfrentadas, así como de grupos étnicos diferentes cuyos modos de vida son incompatibles.

\footnotetext{
12 Giulinani recibió por sus consejos 4,3 millones de dólares, en gran parte pagados por empresarios mexicanos.
} 
Aunque cada rascacielos de la capital galáctica puede considerarse en sí mismo como una comunidad cerrada, es la pequeña ciudad de Dometown, diseñada y edificada por Lando Calrissian en las zonas más hondas de la megalópolis, que corresponden mejor a este tipo de barrio. Para alcanzar la entrada del paraíso subterráneo, es necesario cruzar un verdadero laberinto de túneles y pasillos abandonados desde hace mucho tiempo. El único acceso de este territorio escondido está protegido por una enorme puerta blindada. Al pasar este obstáculo, el visitante descubre un paisaje urbano que recuerda los condominios cerrados que se multiplican en los suburbios de las grandes ciudades americanas:

"La puerta daba acceso a una terraza que dominaba una enorme cueva subterránea en forma de cúpula, cuyo diámetro alcanzaba un kilómetro. La plataforma donde se mantenían [Luke Skywalker y Lando Calrissian] daba sobre una ciudad de bolsillo compuesta de pequeñas casas de piedra y parques verdes. El conjunto era por lo menos llamativo, con su cúpula iluminada, sus pasarelas y sus avenidas limpias y bien mantenidas, sus edificios dispersos, con techos pintados en azul" (MacBride Allen, 1997: p. 102).

Según el mismo modelo, América Latina adoptó el principio del auto-encerramiento para garantizar así el bienestar de las categorías sociales que se sienten hoy en día amenazadas por el crecimiento de la violencia y la inseguridad. Es así como, por ejemplo, cerca de de la capital del Estado de México, la ciudad de Toluca, grandes anuncios publicitarios elogian los barrios protegidos que se construyen en las zonas periféricas de la capital mexiquense, para albergar a las clases medias temerosas del espectáculo aterrador de la ciudad que descubren cada noche en la televisión. Uno de estos promotores señala: "el hogar que tu familia merece”. Al mismo tiempo, otra empresa no duda en autobautizarse como "constructora de ciudades".

En el imaginario de los citadinos, estos espacios protegidos aparecen como verdaderos oasis en un mundo urbano inseguro y violento. En la historieta francesa Moréa, cuya acción transcurre en el año 2082, los cubanos de la alta sociedad casi nunca salen del perímetro vigilado del centro de La Habana, pero les gusta disfrutar de enclaves como el Cubana Country Club (que recuerda a los Country clubes actuales de Buenos Aires), donde pueden con toda tranquilidad jugar al golf y al polo. Esta voluntad de encerramiento les permite escapar de la triste realidad del mundo exterior: "Desde la perspectiva de los pobres, las cosas desagradables ocurren en las calles y eso se llama inseguridad... Desde la perspectiva de los ricos, hay pasto verde, puertas gruesas y cosas bonitas colgadas en la pared" (Arleston, 2005).

En este sentido, Coruscant aparece como una imagen apenas deformada de una realidad que se encuentra por todas partes de nuestro mundo: la ciudad demasiado grande se convierte en una simple máquina de habitar, para usar las palabras de Le Corbusier, donde los modos de vida y las prácticas sociales de la población aceleran el divorcio entre el citadino y el ciudadano. Por consiguiente, la capital galáctica no es sino una representación exagerada de la ciudad de Los Ángeles posmoderna, la que es descrita por Mike Davis (2003) en su conocida obra, Ciudad de Cuarzo. Lo más inquietante es constatar que las soluciones propuestas para arreglar los problemas de esas ciudades reales o imaginarias no tratan de mitigar las causas de la crisis (pérdida del vínculo social, pobreza, racismo, urbanismo criminógeno), sino que se limitan a subsanar sus consecuencias (inseguridad, violencia). Puesto que el sueño virgiliano que inspiraba a Thoreau ya fracasó y la megalópolis alcanzó un punto sin retorno, la única opción que se nos ofrece es adaptar las prácticas de los grupos sociales a la arquitectura impuesta por la modernidad: ¡la ciudad se murió, vivan los guetos!

\section{Referencias bibliográficas}

Allston, A. (2000). Aux commandes: Yan Solo! París: Fleuve noir. (2003). Les chasseurs stellaires d'Adumar. Paris: Fleuve noir.

Alonso, A. (s.f.). Recuperado el 22 de diciembre de 2002, de http://www. streetgangs.com.

Anderson, K. J. \& Moesta, R. (1997). Génération perdue. Paris: Pocket Junior. 
Arleston, S. \& Labrosse, T. (2005). Un parfum d'éternité, Moréa (Vol. 4). Toulon: Soleil Production.

Asimov, I. (1999). Fondation et Empire. En Le cycle de Fondation II: vers un nouvel Empire (pp. 63). París, Omnibus.

Bailly, A. (1995). Encyclopédie de géographie. París: Économica.

Bataillon, C. \& Panabière, L. (1988). Mexico aujourd'hui, la plus grande ville du monde. París: Publisud.

Colin, F. (2006). Invisible. París, Mango.

Congress for the new urbanism, CNU (s.f.). Recuperado el primer semestre de 2007, de http://www.cnu.org.

Cortés, H. (1983). Cartas de relación, segunda carta, 1520. Sepan Cuantos, 7. México: Porrúa.

Crispin, A. C. (1997). Le coup du paradis. París: Fleuve Noir.

Davis, M. (2003). Ciudad de cuarzo: arqueología del futuro en Los Ángeles. Madrid: Ediciones Lengua de Trapo.

Díaz del Castillo, B. (1983). Historia verdadera de la conquista de Nueva España. México: Porrúa.

Duhamel, G. (2003). Scènes de la vie future. Paris: Arthème Fayard.

Estebanez, J. (2006). Les jardins zoologiques et la ville: quelle nature pour le biodôme de Montréal? Annales de géographie, 652.

Fresán, R. (2006). Mantra. Albi: Les editions du Passage du Nord-Ouest.

Garnier, J. P. (1999). Le nouvel ordre local. Gouverner la violence. París: L'Harmattan.

Gruzinski, S. (1996). Histoire de Mexico. Paris: Fayard.

Jacobs, J. (1967). Muerte y vida de las grandes ciudades. Madrid: Ediciones Península.

Kadrey, R. (1988). Metrophage. Ace Books.

Kandell, J. (1988). La capital. The biography of Mexico City. New York: Random House.

Keyes, G. (2002). Renaissance. París: Fleuve Noir.

Lucasfilm Magazine (2006), 62, noviembrediciembre.

Luceno, J. (2001). L'éclipse des Jedi. París: Fleuve Noir.
Luceno, J. (2002). Vent de trahison. París: Presses de la Cité.

Luceno, J. (2005). Labyrinth of Evil. New York: Ballantines Books.

Luceno, J. (s.f.). Recuperado el primer semestre de 2007, de http://www.starwarschicks.com.

MacBride Allen, R. (1997). Traquenard sur Corellia. París: Pocket Science-fiction.

Messmacher, M. (1987). México, Megalópolis. México: SEP.

Morand, P. (1930). New York. París: Flammarion.

Musset, A. (2005). De New York à Coruscant, essai de géo-fiction. París: PUF.

Niño Murcía, S., Lugo Torres, N., Rozo Montejo, C. \& Vega, L. A. (1998). Territorios del miedo en Santa Fe de Bogota. Imaginarios de los ciudadanos. Santa Fe de Bogota: TM editoresObservatorio de cultura urbana.

Oliver, M. (2000). The essential writtings of ralph Waldo Emerson (1836-1844). New York: The modern library classics.

Reaves, M. (2001). Dark Maul: l'ombre du chasseur. París: Presses de la Cité.

Rotker, S. (Ed.) (2000). Ciudadanías del miedo. Caracas: Nueva Sociedad.

Salomon Cavin, J. (2005). La ville, mal aimée. Représentations ainti-urbaines et aménagement du territoire en Suisse: analyse, comparaisons, évolution. Presses polytechniques et Universitaires Romandes.

Salvatore, R. A. (2002). L'attaque des clones. París: Fleuve noir.

Sassen, S. (1991). The global city: New York, London, Tokyo. Princeton: Princeton University Press.

Terada, T. \& Movan, J.D. (2005). Le petit monde (Vol. 1). Vamos, vamos! Dargaud.

Thoreau, H. D. (2004). Walden. Princeton University Press.

Tomas, F. (1999). Villes d'Amérique Latine: plus grandes que leurs problèmes? Revue de géographie de Lyon, 74, 4.

Tyers, K. (2001). Point d'équilibre. París: Presses de la Cité.

Verhoeven, P. (2003). Total Recall (Making of). USA: Studio Canal - Universal 